\title{
Control of infection in hospital wards
}

\author{
ROBERT BLOWERS
}

Public Health Laboratory Service, Middlesbrough

SYNOPSIS Some of the problems of ward management are reviewed. Methods suggested for dealing with them are probably not the ideals that should ultimately be attained but minimum standards to serve as immediate objectives. They concern indications for and methods of isolation, control of infection from staff, environmental contamination, and a few technical procedures. A new type of dressing towel for wounds is described.

Infection acquired in a hospital ward may directly cause disease; or it may create a symptomless carrier. Efforts to control infection must concern both of these processes, because though a symptomless carrier himself suffers no immediate harm, he remains a source from which others may be more seriously infected; moreover, he may re-infect himself if the organisms find their way from the site of carriage to some more susceptible tissue. The success of preventive measures must therefore be judged not only by their immediate effect on disease but also by their control of carrier rates for pathogenic organisms.

There are many ways by which bacteria may reach a patient, but none is necessarily more important than any of the others. So the value of many precautions that are now taken remains uncertain. The hope is sometimes expressed that with more detailed knowledge of the ways by which bacteria spread in a ward we may be able to concentrate on only a few but vitally important precautions, and to relax the many others that make our present system so tedious and so fallible. This hope will be fulfilled only if bacteria behave themselves: if all species and all strains spread in the same way at all times. There is no evidence that this is so and though some broad generalizations may be possible, categorical support or condemnation of any precaution cannot be based on its success or failure on a particular occasion. Assessment of the value of precautions against infection is difficult for yet another reason. Gillespie, Alder, Ayliffe, Bradbeer, and Wypkema (1959) found that several precautions, which by themselves had no discernible effect on infection rates, had a significant effect when applied together. Lack of effect from applying or withdrawing any one procedure must therefore be interpreted very cautiously. With these difficulties of interpretation and much conflicting evidence in mind, the physician or surgeon must choose the methods that he will apply in his own wards.

There are, perhaps, four basic principles of ward procedure for the control of infection: patients who are especially liable to spread infection and those who are especially susceptible to it should not be accommodated in the same ward; the ward staff should not themselves be dangerous sources or vectors of pathogenic organisms; the patients' inanimate environment should not become a reservoir of pathogens; and ward techniques must be those least liable to convey pathogens. For each of these principles, I make no attempt to define the ideals that are theoretically desirable. For the present it seems more useful to suggest the minimum standards we should try to reach. Nor can a review such as this cover all aspects of ward management. Among the many important problems not considered here are the pre-operative treatment of skin, methods for disposal of contaminated articles, and the proper use of antibiotics.

\section{ISOLATION AND SEGREGATION}

Here is a suggested list of infections for which patients should be removed from an open ward. They should also be moved when they are suffering from disorders making them particularly susceptible to infection, or when being treated with certain drugs which enhance susceptibility to infection.

1 THE ACUTE SPECIFIC FEVERS, e.g., measles, mumps, chickenpox, whooping-cough, scarlet fever (and other streptococcal diseases), diphtheria.

2 OPEN TUBERCULOSIS.

3 INTESTINAL INFECTIONS: (a) Shigella dysentery; (b) Salmonella infections, i.e., typhoid and paratyphoid fevers, food poisoning, symptomless carriers; (c) E. coli enteritis of infants and symptomless 
carriers of locally pathogenic strains; $(d)$ unexplained diarrhoea.

\section{STAPHYLOCOCCAL DISEASE.}

5 INCREASED SUSCEPTIBILITY TO INFECTION: (a) Treatment with steroid drugs; $(b)$ acute leukaemia, especially during treatment with marrow-toxic drugs; (c) agranulocytosis; $(d)$ uraemia; (e) burns and skin grafts.

Many of these indications are so obvious that no justification is needed here. Of the others, staphylococcal infections deserve special discussion.

It is remarkable that in many wards where elaborate precautions against staphylococcal infection are taken, little importance is attached to the apparently obvious one of removing patients with frank sepsis. Thus, patients who have been admitted with Staphylococcus aureus pneumonia, empyema, osteomyelitis, breast and other abscesses, urinary tract infection, and septic dermatitis are regularly treated in open wards alongside uninfected patients. Perhaps even more dangerous are those patients who became infected with staphylococci in hospital, because the organisms involved are more often epidemic strains and resistant to antibiotics; in this category are patients suffering from Staph. aureus enterocolitis, septic burns, post-operative wound sepsis, and the various forms of neonatal sepsis.

When patients must be removed from an open ward for any of these reasons more isolation accommodation than is usual must be provided, and until it is available, some form of priority must be devised. The very profuse discharge of organisms from patients with staphylococcal enterocolitis, pneumonia, septic dermatitis, and burns requires that they should be isolated. For patients who have been infected in hospital and from whom organisms are discharging profusely the need for isolation is still more imperative.

It is sometimes objected, however, that isolating septic patients cannot be expected to control infection while symptomless carriers of Staph. aureus remain in the ward. This is probably true during a major outbreak of sepsis caused by a highly virulent organism, when it may indeed be necessary to remove carriers of the epidemic strain, as well as the septic patients to break the chain of infection. In non-epidemic times, however, most of the symptomless carriers harbour strains that seem to lack virulence or a high degree of transmissibility, and these patients can safely remain in a wellmanaged ward. But the organisms in actual lesions have already proved their virulence and it seems unwise to give them an opportunity to prove their powers of spread.
METHODS OF ISOLATION For the acute specific fevers and intestinal infections the patient should be transferred to an infectious diseases hospital. For staphylococcal diseases needing surgical treatment this is rarely practicable though when it is, full use should be made of isolation hospitals, especially during a serious outbreak. The value of the various degrees of 'isolation' available in general hospitals has not been defined and careful bacteriological studies are very much needed.

Barrier nursing in an open ward depends on eliminating infection by direct and indirect contact and may actually do this if an exceptionally high standard of nursing is assured. It cannot, however, prevent airborne infection though it is not yet certain how great a part this plays in the spread of staphylococci in a ward. By studying the spread of Staph. aureus from known infant carriers and from one nurse, Wolinsky, Lipsitz, Mortimer, and Rammelkamp (1960) concluded that contact rather than airborne spread accounted for almost all the infections. But individuals vary greatly in their powers of aerial dissemination of staphylococci (Hare and Thomas, 1956; Hare and Ridley, 1958; Eichenwald, Kotsevalov, and Fasso, 1960), and studies of airborne spread will have to be made with subjects who are known to be profuse 'dispersers' before final conclusions can be reached on the importance of this method of studying spread of infection. For all this, there are many examples of failure to control the spread of Staph. aureus by barrier nursing, and, whether these are due to inadequacy of the system or failure to apply it properly, it cannot be recommended as a reliable method.

Isolation in a ward side-room is perhaps more often successful but failures are many if the patient is simply moved into it and attended in the usual way by nurses who also have to deal with uninfected patients in the main ward. Side-ward isolation should therefore always include the full ritual of barrier nursing as a safeguard against contact infection. Thus, all equipment needed for the patient is kept in the isolation room or is disinfected or destroyed as soon as it is brought out; ward staff wear gowns (which are kept in the isolation area) and masks when attending the patient and wash their hands before and after doing so.

Isolation rooms for septic patients should be ventilated by simple exhaust fans discharging to the outside so that air flows into them and not from them to the main ward. For patients who are being isolated for protection against infection, airflow in the opposite direction is theoretically needed but a reasonable compromise is to switch off the exhaust fan and to rely on natural ventilation from 
an open window. The door of an isolation room should be kept closed.

Full isolation requires nurses who do not attend uninfected patients, and a separate room for each patient in a building set away from the general wards. Isolation units such as this are not part of the usual hospital design in Britain but they have sometimes been improvised during an emergency and, remaining in use afterwards, have shown their value by apparently limiting the spread of infection from occasional septic patients during non-epidemic times.

Only recently has the number of isolation rooms required for the control of infection become the subject of quantitative study. Results of current studies are not yet available but it seems likely that at least $30 \%$ of surgical and $15 \%$ of medical beds will be required. In most British hospitals such generous isolation facilities are not yet available and until they are, anything approaching full control of staphylococcal infection will be difficult.

Segregation During an outbreak of sepsis when there are more patients for isolation than there are rooms to put them in, an acceptable substitute for isolation is segregation, whereby infected patients are collected together in a special ward. This does not, of course, prevent them from re-infecting each other and it is a method that can only be accepted if there is no possibility of proper isolation. It is, however, infinitely preferable to leaving the septic and clean patients together in the same ward.

\section{PREVENTION OF INFECTION FROM WARD STAFF}

INFECTIOUS DISEASES Members of the hospital staff who remain on duty with even minor infections may be more dangerous than patients suffering from serious infective conditions. Nurses and doctors, perhaps from a mistaken sense of duty, often continue to attend patients while suffering from a sore throat, undiagnosed diarrhoea, purulent discharge from nose or ear, or staphylococcal sepsis such as generalized furunculosis, boils, styes, paronychia, and septic cuts or burns. Nurses are sometimes discouraged from reporting sick for these 'trivial' reasons and many doctors believe that their services are too valuable for them to hand over to a colleague for a few days. It is not easy to lay down general rules for behaviour of staff during minor illness or sepsis but the minimum requirements (apart from the obvious ones) should be:

Completely off duty for diarrhoea until proved bacteriologically safe, sore throat; one large discharging staphylococcal lesion; generalized furunculosis with several discharging lesions.

Not to assist at any aseptic procedure (e.g., wound inspection, wound dressing, or injection), with a discharging lesion on any part of the body; any septic lesion, whether discharging or not, on the hand or forearm.

SYMPTOMLESS CARRIERS The routine seeking and exclusion from duty of all carriers of pathogenic organisms amongst ward staff is impracticable and probably not necessary. As with the patients, however, it may be needed during an outbreak due to a clearly recognizable organism. Carriers of Staph. aureus are detected by swabbing the anterior nares. Phage typing should be used to identify the epidemic strain and antibiotic sensitivity patterns are sometimes useful for more rapid but partial identification. Clearance of the carrier state is often difficult but treatment that sometimes succeeds is the thrice-daily application of neomycin-chlorhexidine cream ${ }^{1}$ to the noses of carriers for 10 days. In addition when washing and bathing they should regularly use toilet soap $^{2}$ or cream $^{3}$ containing hexachlorophene or tetrachlorsalicylanilide 4 . Persistent skin carriage is often controlled by the permanent use, both on and off duty, of these soaps even though carriage by the nose remains uncontrolled.

MECHANICAL CONVEYANCE OF ORGANISMS BY WARD STAFF Contamination of hands, and spread from them, can be reduced by applying these rules:

Use forceps or rubber gloves for all wound dressings and examinations and for handling drainage tubes, tracheal tubes, catheters, and other heavily contaminated objects.

Wash the hands before and after any procedure for which gloves, forceps, or sterilized equipment are used; after changing an infant's napkin or dressing the umbilicus; after rounds of temperature taking, bedmaking, or bedpans; after any item of service for a patient who is (or should be) isolated; after defaecation and before and after each spell of ward duty.

For all these purposes a 'surgical scrub' probably has no advantage over thoroughly washing the hands with soap and water and drying them on a clean towel. Conveyance of pathogens is reduced if the soap contains hexachlorophene (Lowbury and Lilly, 1960). Automatic roller-towel dispensers and good-quality paper towels are both satisfactory and should replace the communal towel. It may sometimes be preferable to use a sterile towel but when this is not done drying the hands on a clean but unsterilized towel is safer than leaving them wet.

\footnotetext{
${ }^{1}$ Naseptin cream (Imperial Chemical Industries Ltd.).

${ }^{2}$ Derl (Roberts Windsor Ltd.); Cidal (Bibby Ltd.).

${ }^{3}$ Phisohex (Bayer Products Ltd.).

- Breeze (Crosfields (C.W.G.) Ltd.).
} (a) (n) 
Clothing The aprons and dresses of nurses attending infected patients, especially children who must often be lifted and carried, are sometimes heavily contaminated after only one day's wearing (Potter and Blowers, unpublished observations in a burns unit). Thus there seems some justification for a one-piece uniform, changed daily, instead of the usual daily clean apron and a dress that is worn for a week. Besides its possible bacteriological advantages, this means one less item of laundry each week than does the older system.

Cotton gowns offer only incomplete protection against contamination in either direction but they seem to be of some value (Cook, Parrish, and Shooter, 1958) so they should be worn over the uniform at least during wound dressings and during attention to patients in isolation. Impervious plastic gowns, disinfected by wiping with a hypochlorite solution containing $1 \%$ available chlorine ${ }^{1}$, give better protection and seem preferable to cotton gowns for barrier nursing and isolation techniques.

\section{CONTROL OF ENVIRONMENTAL CONTAMINATION}

For many years, and especially in the last few, bacteriologists have been busy discovering inanimate reservoirs of pathogenic organisms in hospitalswalls, floors, ceilings, and furniture; bed-clothes, curtains, and crockery; and the air-while methods for disinfecting them have been increasing the cost and complexity of ward management. These activities should certainly not be discouraged, because the discovery of reservoirs and the invention of methods for disinfecting them are essential preliminaries to the full study of such organisms. It cannot be denied that disinfection of the whole environment is essential when there has been known heavy contamination with dangerous organisms. The need for frequent and energetic environmental decontamination at other times is less certain. Theoretically, it should reduce the risk of infection at any time, but whether or not it does so significantly has not been conclusively shown. Unfortunately, clear evidence on this point is not easy to obtain because, as has already been pointed out, the complexity of bacterial spread makes the evaluation of each pathway very difficult. Enthusiasts for particular methods will no doubt continue to apply them but it is hoped that they will accept responsibility for the steady, even though laborious, collection of evidence to support their views, rather than becoming tedious crusaders for unproven causes.

1 For example, Chloros (Imperial Chemical Industries Ltd.) diluted 1 in 10, wiped on and left to dry.
My purpose here is not to enumerate all the disinfection procedures that might do some good, but to suggest, in the light of available evidence though without quoting it all in detail, minimum standards for environmental hygiene in hospital wards. Still higher standards may be desirable but those suggested are by no means universal and should serve as reasonable targets for the next few years.

WALLS, FLOORS, CEILINGS, AND FURNITURE The number of pathogens on these surfaces can be kept low by applying high standards of domestic cleanliness. This means that floors should be washed each morning, and dust and fluff should be taken up by vacuum cleaner after bed-making rounds. For routine purposes, mopping with very hot water, at not less than $70^{\circ} \mathrm{C}$. $\left(160^{\circ} \mathrm{F}\right.$.), and a synthetic detergent is sufficient. The routine use of disinfectants for washing floors gives little better results and most of those cheap enough for the purpose cause a persistent and unpleasant smell. Bacteria may multiply profusely in dirty mops and buckets of water if these are left for several hours. After each use the bucket and mop should therefore be rinsed with boiling water.

Broom-sweeping often raises as much dust as it collects, and slit-sampling shows an enormous increase in the number of airborne organisms while it is going on. This can be reduced by oiling the floors but the process is only really satisfactory for wood and not for modern non-absorbent floors. The best solution is to discard brooms and use vacuum cleaners. Built-in suction points have some advantages but are expensive to install and are less convenient than portable electric machines. Elsewhere in this issue, Dr. Bate discusses the types of machine that are safe for use in hospital (page 32).

Walls and ceilings cannot conveniently be cleaned as often as floors; nor does this seem necessary because dust collects on them more slowly and is less often disturbed from them than from floors. Perhaps a reasonable rule to follow here is that they should never be visibly dirty. The washing methods already described for floors should therefore be applied often enough to ensure this. It is a disturbing thought that there are still hospitals where even this standard is not reached.

Ledges, furniture, and beds should be dusted daily with a damp cloth.

These are the routine methods. If, however, an isolation room has been occupied by a patient suffering from infectious disease (and this includes staphylococcal sepsis) specific decontamination is needed. The whole room may be treated by sealing it, spraying water to increase humidity, then 
generating formaldehyde and leaving the room closed for six hours. For each $1,000 \mathrm{cu}$. $\mathrm{ft}$. of room space, $5 \mathrm{oz}$. (150 g.) potassium permanganate is added to $10 \mathrm{oz}$. $(280 \mathrm{ml}$.) of formalin. Sulphur dioxide is ineffective. A satisfactory and often more convenient method is to wash all surfaces, furniture, and the bed with hypochlorite solution (see footnote on page 21) to which has been added some household detergent.

If a septic patient has been barrier-nursed in an open ward, it may suffice to wipe over the bed and bedside furniture in this way. But if a large ward has been closed because of widespread sepsis it should not be re-opened until the whole room has been disinfected by one of these methods.

SCREENS AND CURTAINS Separate pull-round curtains for each bed in an open ward harbour more dust than a few sets of portable screens. Their social advantages are so great, however, that it seems unjustifiable to condemn them on theoretical and unevaluated bacteriological grounds. It is arbitrarily suggested that the curtains be removed and disinfected each month, when the overhead rails and runners should also be damp-dusted. Cotton curtains should be of colour-fast material so that they may be laundered, and thus disinfected by boiling. Plastic materials have the theoretical advantage that they can be wiped with a disinfectant in situ or in a ward annexe; but this occupies more of the ward staff's time than removing cotton curtains and sending them to the laundry, so is often postponed for long periods. Thompson and Webb (1960) describe fibre-glass curtains which can be washed at high temperature in the laundry or may be dipped in a disinfectant in the ward annexes and re-hung almost immediately.

BEDDING There is no doubt that bed-clothes can become heavily contaminated with pathogenic organisms from a patient's lesions or from sites of symptomless carriage. Sheets are adequately disinfected by the boiling they normally get during laundering; but hospital blankets are rarely washed, and then only by a low-temperature process which neither removes nor destroys bacteria. It is argued that contaminated blankets, carrying organisms from a long succession of patients in each bed, may directly infect a new occupant, that organisms scattered from them into the air during bed making may help to maintain high nasal carrier rates of staphylococci derived from septic lesions; and that hospital beds should therefore be equipped with disinfected blankets for each new occupant. The theoretical advantages of this are clear, but there are conflicting reports of its actual value. These are perhaps summarized by the experiences of Gillespie et al. (1959) and Gillespie, Simpson, and Tozer (1958) who found that regular blanket disinfection as the only new precaution had no detectable influence on Staph. aureus sepsis or carrier rates, but when applied with other precautions appeared to play a part in their control.

Whether or not this fairly expensive routine is wholly justified on bacteriological grounds, apart from its obvious aesthetic desirability, remains to be shown. In the meantime, the following routine is suggested as a minimum standard:

(1) Sheets should be laundered at least weekly and whenever a bed is vacated.

(2) Blankets, mattresses, and pillows should be disinfected $(a)$ every three months; $(b)$ whenever visibly soiled; $(c)$ after use by any infected patient who has been isolated or should have been isolated according to the indications already given; $(d)$ after use by every patient during an outbreak that has resisted the routine precautions; $(e)$ before reopening a ward that has been closed because of infection.

Woollen blankets may be disinfected by washing them at the usual low temperature and using a detergent combined with a quaternary ammonium or other suitable disinfectant substance'. It was once hoped that incorporation of the disinfectant in the last rinse instead of the washing stage would confer self-disinfecting properties on the blankets. But though fibres from blankets so treated cause zones of inhibition on a culture plate seeded with staphylococci, there is no appreciable killing of organisms in the blanket itself during use, presumably because the disinfectant does not act when dry. Woollen blankets may also be disinfected by hightemperature washing provided this is just below boiling point (British Launderers' Research Association and International Wool Secretariat, 1959). This causes no more damage to the blankets than the low-temperature wash but woollen blankets will stand only about 60 washes in any case, so disinfecting them regularly must always be fairly expensive. Cotton cellular or terry-towelling blankets are easily disinfected by washing at boiling point or just below and will stand several hundred such treatments (Blowers, Potter, and Wallace, 1957). For pillows and mattresses enclosed in plastic covers, it is usually sufficient to wipe the covers with hypochlorite solution.

CROCKERY This should be washed, or rinsed after washing, in water at $60^{\circ} \mathrm{C}$. $\left(140^{\circ} \mathrm{F}\right.$. $)$.

\footnotetext{
1 For example, Vantropol BQ (Imperial Chemical Industries Ltd.); Hytox (Domestos Ltd.); Steravol (Laporte Ltd.); Comprox-panacide (B.P. Detergents Ltd.).
} 


\section{NURSERY EQUIPMENT}

The procedures already given are obviously applicable in nurseries but three pieces of equipment on which many babies are successively placed each day need special attention. Nursery baths (and indeed baths in all wards) should be disinfected after each use by the effective method of Boycott (1956). One to two gallons of very hot water are run into the bath; $\frac{1}{2} \mathrm{fl}$. oz. of undiluted hypochlorite solution and enough domestic detergent for effective cleaning is added to it and the bath is thoroughly mopped with this mixture. The pans of the baby scales should be wiped after each use with a non-irritant disinfectant such as chlorhexidine ${ }^{1}$. This can be properly done only if metal or plastic pans replace the widely-used wicker ones. The tables on which babies are placed for changing their napkins or other attention should be similarly treated and covered by a freshly laundered towel for each baby. But the risk of cross-infection is reduced if as many as possible of these tasks are done with the babies in their own cots.

One other procedure of vital importance in the prevention of nursery epidemics is the preparation and bottling of feeds for the babies. This should be done by a nurse who does not handle the babies and in a department set aside and equipped for the purpose. Suitable equipment and recommended methods cannot be fully discussed here and the reader is referred to the detailed recommendations of Perkins (1956).

THE AIR There is yet no conclusive evidence of the importance of airborne infection in wards. Direct infection by this route of properly covered surgical wounds seems unlikely, but staphylococcal infection of the respiratory tract causing pneumonia or symptomless nasal carriage seem real possibilities. Plenum ventilation with a high exchange rate as used in operation theatres would reduce the number of airborne organisms but the cost of applying it to a whole hospital would be enormous. Recirculation ventilation of wards, with filtration to remove bacteria, is less expensive but its effect on infection is not known. Recirculation systems without filtration and serving a whole hospital may actually assist the spread of infection between wards.

Hudson, Sanger, and Sproul (1959) suggest treating the air and entire ward contents with a long-acting disinfectant, bis (n-tributyl) tin oxide. This reduces the number of airborne organisms by about four-fifths but the effect on infection is not yet known.

${ }^{1}$ Hibitane (Imperial Chemical Industries Ltd.); $0.5 \%$ alcoholic solution or the $1 \%$ obstetric cream are both effective for scale pans.
The most recently proposed method (Elek and Fleming, 1960) is to spray the ward with a new synthetic penicillinase-resistant penicillin. This must surely remain experimental until the properties of the drug have been more fully studied. Before it can be contemplated as a routine measure, much more must be known about its effect in creating or selecting resistant strains, in leaving the way open for serious Gram-negative and Candida infections, and in causing human sensitivity. At present, therefore, control of airborne infection in wards must still depend on preventing dissemination of organisms by isolation and by other techniques already recommended.

\section{SPECIAL TECHNIQUES}

Of the many special ward techniques that give opportunity for infection, only two will be discussed here: wound dressings and continuous drainage methods.

WOUND DRESSINGS Techniques for wound dressings must allow no opportunity for infection to or from the wound by direct or indirect contact. Reliable methods for a dresser and assistant or for an unassisted dresser are described in a Ministry of Health report (1959) so are not given in detail here. The number of ward sisters and sister tutors who have neither seen nor heard of this publication is remarkable. Because the importance of training nurses in the control of infection is so great this deficiency should be put right.

The setting of dressing trolleys is simplified and thus made safer by using individual dressing packs, disposable gallipots, and disposable paper bags for dirty dressings.

One further improvement in dressing technique is now available, namely, the use of water-repellent dressing towels. The usual dressing towels are waterabsorbent so that wet instruments placed on them may be contaminated when the water soaks through to an unsterile table top beneath (Fig. 1). It is sometimes necessary to put a towel over the bedclothes around the wound and though instruments should not be placed on this, they sometimes are, when the risk of contamination is even greater. Some types of disposable paper dressing towels are even more absorbent than cotton so may increase rather than reduce, as is claimed, the risk of infection. Cotton fabrics of the Ventile ${ }^{1}$ type do not allow water to soak through it unless it is very hot. These materials are being successfully used for the sleeves of surgeons' gowns to prevent skin organisms passing through to the wound when the sleeves are wetted,

${ }^{1}$ Messrs. John Southworth \& Sons Ltd., Clitheroe, Lancashire. 


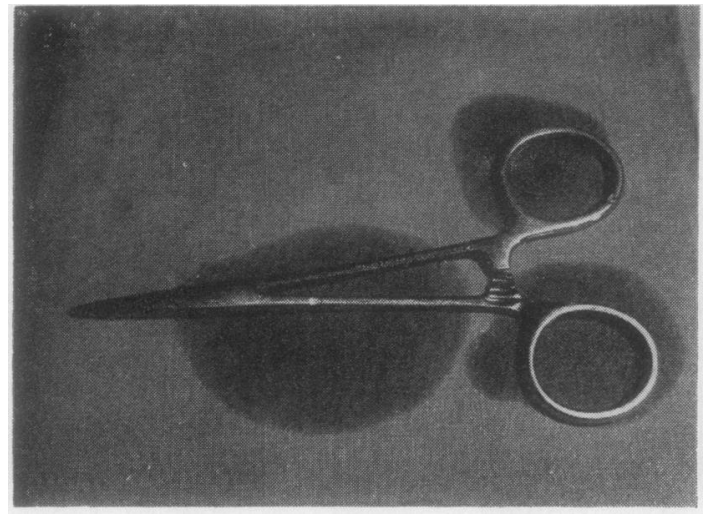

FIG. 1. Wet forceps on an ordinary cotton dressing towel. The water soaks through to the underlying surface, from which the instrument may then be contaminated.

as they often are during an operation. A more recent application is to use Ventile fabrics for dressing towels to reduce the risk of contamination from underlying surfaces. Drops of water remaining on a Ventile dressing-towel without soaking through are shown in Fig. 2.

Wound Dressing Rooms The value of specially ventilated wound dressing rooms has been clearly shown by Bourdillon and Colebrook (1946) and by Lowbury (1954). For patients in open wards all wounds, whether infected or clean, should therefore be done in a specially equipped and ventilated dressing-room. For patients already in isolation, however, the dressing should be done in the isolation room unless it is so complicated that the special facilities of the dressing-room are essential.

A dressing-room that is used for septic work soon becomes a concentration area for pathogenic organisms unless it is thoroughly cleaned after every session of dressings and unless it is specially ventilated. Positive-pressure ventilation, as recommended by Bourdillon and Colebrook, prevents contamination of clean wounds with airborne organisms from the wards. For a dressing-room that is often used for septic wounds and closely communicates with a ward, however, this may cause heavy contamination of the ward so a balanced ventilation system with input and extraction fans of equal capacity is preferable. A rapid turnover of air is needed and for rooms of up to $2,000 \mathrm{cu}$. ft., a ventilation rate of $650 \mathrm{cu}$. $\mathrm{ft}$. per minute will clear heavy aerial contamination in about 10 minutes. It is rarely possible to equip dressing-rooms with the complicated and expensive ventilation plant of the type used in operating theatres. A simple and inexpensive plant suitable for dressing-rooms is

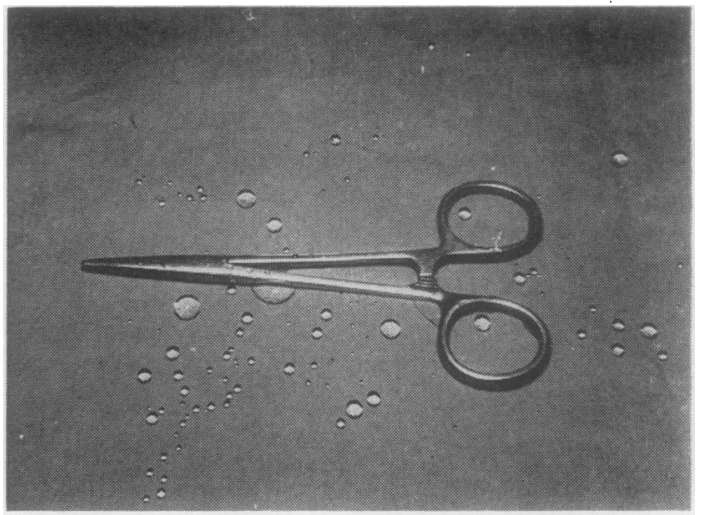

FIG. 2. Wet forceps on a Ventile cotton dressing towel. Water remains as globules which neither wet the surface nor pass through the material.

described by Williams, Blowers, Garrod, and Shooter (1960).

CONTINUOUS SUCTION APPARATUS Surgery of the urinary tract is complicated by post-operative infection perhaps more often than any other type of surgery. Most of this infection depends on common but avoidable faults of indwelling catheter drainage systems. Pyrah, Goldie, Parsons, and Raper (1955) and Miller, Gillespie, Linton, Slade, and Mitchell $(1958,1960)$ show that post-operative urinary sepsis is all but eliminated by using closed drainage apparatus. In many wards, any urine drainage system using a bunged bottle is accepted as a closed one but this is far from being so. Miller and his colleagues showed that even temporary disconnexion of the system for bladder irrigation or for some other reason allowed infection to occur as often as did an open drainage system. Their apparatus, which is strongly recommended, includes an irrigation attachment that can be used without breaking the closed system. Failure to sterilize an already infected bladder is often due to its constant reinfection by organisms that ascend from the accumulated urine in the 5 bottle. This is prevented by putting $100 \mathrm{ml}$. of $\tilde{O}$ formalin in the bottle.

Drainage from the thoracic cavity, too, often 0 allows infection unless a closed system is used. For 0 this, however, a disinfectant cannot be put in the $\frac{D}{\mathbb{D}}$ bottle because it may be aspirated into the chest $\stackrel{\mathcal{D}}{?}$ during coughing. Contamination of the fluid should $\square$ be prevented by a cottonwool plug in the air outlet tube and by changing the bottles with the aseptic care of a surgical operation.

I am grateful to Dr. Stanley Wray and Mr. William Bound for their help with the photographs. 


\section{REFERENCES}

Blowers, R., Potter, J., and Wallace, K. R. (1957). Lancet, 1, 629. Bourdillon, R. B., and Colebrook, L. (1946). Ibid., 1, 561 and 601.

Boycott, J. A. (1956). Ibid., 2, 678.

British Launderers' Research Association and International Wool Secretariat (1959). High Temperature Laundering of Woollen Hospital Blankets. London.

Cook, Josephine, Parrish, J. A., and Shooter, R. A. (1958). Brit. med. J., 1, 74.

Eichenwald, H. F., Kotsevalov, Olga, and Fasso, Lois A. (1960). Amer. J. Dis. Child., 100, 161.

Elek, S. D., and Fleming, P. C. (1960). Lancet, 2, 569.

Gillespie, W. A., Alder, V. G., Ayliffe, G. A. J., Bradbeer, J. W., and Wypkema, W. (1959). Ibid., 2, 781.

—, Simpson, K., and Tozer, Rosemary C. (1958). Ibid., 2, 1075.

Hare, R., and Ridley, M. (1958). Brit. med. J., 1, 69.

-, and Thomas, C. G. A. (1956). Ibid., 2, 840.
Hudson, P. B., Sanger, G., and Sproul, Edith E. (1959). J. Amer. med. Ass., 169, 1549.

Lowbury, E. J. L. (1954). Lancet, 1, 292.

and Lilly, H. A. (1960). Brit. med. J., 1, 1445.

Miller, A., Gillespie, W. A., Linton, K. B., Slade, N., and Mitchell, J. P. (1958). Lancet, 2, 608 .

—, Linton, K. B., Gillespie, W. A., Slade, N., and Mitchell, J. P. (1960). Ibid., 1, 310.

Ministry of Health (1959). Central Health Services Council Report: Staphylococcal Infections in Hospitals. H.M.S.O., London.

Perkins, J. J. (1956). Principles and Methods of Sterilization. Thomas, Springfield, Illinois.

Pyrah, L. N., Goldie, W., Parsons, F. M., and Raper, F. P. (1955). Lancet, 2, 314

Thompson, K. S., and Webb, Mary J. (1960). Ibid., 1, 286.

Williams, R. E. O., Blowers, R., Garrod, L. P., and Shooter, R. A. (1960). Hospital Infection. Lloyd-Luke, London.

Wolinsky, E., Lipsitz, P. J., Mortimer, E. A. Jr., and Rammelkamp, C. H. Jr. (1960). Lancet, 2, 620. 